International Journal of Development, Vol.8, No.(1) (2019): 55-63

ISSN: 2314-5536 (print)

e-ISSN: 2314-5544 (Online)

www. ijd.byethost13.com

e-mail: fas_ijd@yahoo.om

\title{
Effect of anionic surfactant on mesoporous particles for removal of methylene blue
}

\author{
Abeer Emam ${ }^{1}$, Lalia Foud ${ }^{1}$, Asmaa Kamal Eldeen ${ }^{1 *}$, Marwa Ibrahim ${ }^{2}$ and Mona Seif ${ }^{2}$ \\ 1- Department of Chemistry, Faculty of Science, Al-Azhar Univ. (Girl branch), Cairo, Egypt \\ 2- Department of Chemistry, Faculty of Education, Ain Shams Univ., Roxy,Cairo, Egypt \\ *Asmaaelzayat146@gmail.com
}

\begin{abstract}
$\mathrm{ZnO}-\mathrm{SiO}_{2}(\mathrm{ZSnc})$ nanoadsorbent was prepared by sol-gel method in the presenceof SDS as anionic surfactant $\left(10^{-3}, 6 \times 10^{-4}\right.$, and $\left.10^{-4} \mathrm{~mol} / \mathrm{l}\right)$, for removing methylene blue (MB) from wastewater. The papered nanomaterials were characterized by XRD, TEM and surface area analysis. The factors affecting adsorption were thoroughly investigated and optimized. The mechanisms and kinetics of adsorption were explored.
\end{abstract}

Keywords: $\mathrm{ZnO}-\mathrm{SiO}_{2}$; Cationicdyes; Thermodynamic; surfactant; Adsorption.

\section{INTRODUCTION}

Many countries needed access to clean and safe water for municipal use and other usages $^{[1]}$. Recently, the scientists are starting to use the nanomaterial in the adsorption process for wastewater treatment. Adsorption considered an effective methodology for the elimination of organic and inorganic pollutants and dyes from wastewater ${ }^{[2]}$. The Adsorption method affords also majority resilience in the styling of the attempt adsorbent for the intention pollutant as ease and high operational elasticity. MB is used in some medical uses, it can also be vastly used in coloring paper, dyeing cotton, wools, coating for paper stocks, etc. Although MB is few hazardous, it can reason some harmful effects. Sharp exposure to MB will cause altitude heart rate and tissue necrosis in humans Nonetheless, MB can reason eye burns which likely responsible for perpetual infection to eyes of human and animals ${ }^{[2,3]}$. $\mathrm{ZnO}-\mathrm{SiO}_{2}$ as example of composite material have utilized in several applications, e.g. to eliminate $\mathrm{H}_{2} \mathrm{~S}$ from gas inflow ${ }^{[4]}$. These physic-chemical properties can modify different techniques like doping and prep ration methods. The preparation method can be modified using a different additive like the surfactant.Surfactant molecules are forming each hydrophilic (water-loving polar) and hydrophobic moieties (water-repelling group) the hydrophobic group containing of aliphatic or aromatichydrocarbon chain.

The hydrophilic group has perhaps ionic or nonionic in nature. Negative charges tote by the solid ionic surfactant particles due to a strong repulsive force for each the particles; raise the solvency of the hydrocarbon chain and hydrophilic group. Surfactantsthat don't dissolve structure micelles, which are spherical aggregates between the ionized and nonionized surfactant particles. These micelles form the cause of an affinity between the hydrocarbons tails appropriate according to van der Waals forces ${ }^{[5]}$.Structural difference in three surfactants leads to different hydrophobicity and an increase in aggregation number of surfactant molecules in a micelle caused by the decrease in hydro-phobicity ${ }^{[6,7]}$ results in increasing the number of binding sites and the tendency of $\mathrm{MB}$ to attach with nanoparticles. The spectral changed which regard to dye, [8,9] observed in its the arrival to aggregate surfactants are varying monomers, micelles and dye combinations ${ }^{[10]}$. This research aims tostudy the effect of (ZSnc) on the physic-chemical properties for removal dye application. 
Abeer Emamet al.

\section{EXPERIMENTAL METHODS}

\section{1-Synthesis of $\mathrm{ZnO}-\mathrm{SiO}_{2}$ ( $\mathrm{ZSnc}$ )}

All chemicals were supplied by Sigma and Aldrich and used as adduced. ZSnc prepared by sol-gel and modified using a different concentrations ofSDS $\left[\mathrm{CH}_{3}\left(\mathrm{CH}_{2}\right)_{11} \mathrm{SO}_{4} \mathrm{Na}\right]$. This method has been done in three steps. Firstly, different concentrations of surfactant at $\left[10^{-4}, 6 \times 10^{-4}\right.$ and $\left.10^{-3} \mathrm{~mol} / \mathrm{l}\right]$ are dissolved in the lowest proportion of distilled water. The second step, a variety of the concentrations of surfactant solution are placed on an aqueous solution of $50 \%$ wt., of $\mathrm{Zn}\left(\mathrm{Ac}_{3}\right)_{2} \cdot 6 \mathrm{H}_{2} \mathrm{O}$. That step results in its formation nanocomposite of $\mathrm{ZnO}$ to $\mathrm{SDS}$. At last step, the preparation of $\mathrm{SiO}_{2}$ at a collide suspension particles according to the following process, $2 \mathrm{ml}$ (TEOS) Tetraethyl orthosilicate was mixed with $23.5 \mathrm{ml}\left(\mathrm{CH}_{3} \mathrm{OH}\right)$ methylene alcohol, $14.5 \mathrm{ml}$ deionized water and $\left(\mathrm{HNO}_{3}\right)$ nitric acid $0.08 \mathrm{ml}$ beneath vigorous stirring for $1 \mathrm{hr}$. After that, the latter solution was kept under vigorous stirring for $60 \mathrm{~min}$. The reaction was achievedat room temperature. The prepared samples have left for $24 \mathrm{hr}$ at last, the samples precipitates were dried in the oven at $80^{\circ} \mathrm{C}$, pursue by calcination at $550{ }^{\circ} \mathrm{C}$ for $2 \mathrm{hr}$ in air. In comparison, $50 \%$ wt., of ZSnc is prepared by sol-gel without modification surfactants.

\section{2- Characterization}

Powder X-ray diffraction analysis (XRD) process was achieved by Shimadzu XRD6000 besides $\mathrm{Cu}$ radiation $\lambda=1.54056 \AA$ with a scan rate of $4^{\circ}$ in $2 \theta / \mathrm{min}$. The morphology of nanoparticles was measured using transmission electron microscope (TEM) Hitachi 7500. The surface properties of the nanomaterialwere determined by Quanta chrome Instruments, NOVA Touch LX4 (USA). UV-visible spectroscopy (UV-vis/DR) was fulfilled on JASCO $\mathrm{V}-550$ spectrophotometr (Japan) supported with an integrating sphere accessory.

\section{Adsorption experiments}

The methylene blue was used as a model dye example in the adsorption experimental. Solution of $\mathrm{MB}$ of different concentrations were stirred at room temp was $0.1 \mathrm{gm}$ of the adsorbent (ZSnc) for $2 \mathrm{hr}$. At several time intervals, the solutions separate utilize a centrifuge at $4500 \mathrm{rpm}$ for $5 \mathrm{~min}$. The residual concentration of $\mathrm{MB}$ was anatomized by UV-Vis spectrophotometer. The absorption band of MB was found at a maximum wavelength $\left(\lambda_{\max }\right)$ of $664 \mathrm{~nm}$.

Many of arithmetical models can be utilized to depict experiential data of adsorption isotherms.Namely, isotherm equations, the Langmuir and Freundlich, have characterized to fit the experiential isotherm data of MB adsorption by modified nanoparticles (ZSnc). Furthermore the kinetic experimental data were examined by pseudo first order kinetics, pseudosecondorder kinetics and intra-particle diffusion. As in all equations parameter listed in Table (1).

Table 1. Data Processing parameters Tools.

\begin{tabular}{|c|c|c|c|}
\hline No & & Parameters & Formula \\
\hline \multirow{2}{*}{1} & \multirow{2}{*}{ Isotherms } & $\begin{array}{l}\text { Langmuir } \\
\text { Separation factor }\end{array}$ & $\begin{aligned} \mathrm{C}_{\mathrm{e}} / \mathbf{Q}_{\mathrm{e}} & =1 / \mathbf{Q}_{0} \mathbf{b}+\mathrm{C}_{\mathrm{e}} / \mathbf{Q}_{0} \\
\mathbf{R}_{\mathrm{L}} & =1 /\left(1+\mathrm{bC}_{0}\right)\end{aligned}$ \\
\hline & & Freundlich & $\operatorname{Inq}_{\mathrm{e}}=\operatorname{Ink}_{\mathrm{f}}+\frac{1}{n} \operatorname{InC}_{\mathrm{eg}}$ \\
\hline \multirow{3}{*}{2} & \multirow{3}{*}{ Kinetics } & Pseudo-first order & $\operatorname{In}\left(q_{e^{-}} q_{t}\right)=\operatorname{In} q_{e^{-}}-k_{1} t$ \\
\hline & & Pseudo-second order & $\frac{\mathrm{t}}{\mathrm{q}_{\mathrm{t}}}=\frac{1}{\mathrm{k}_{\mathrm{z}} \mathrm{q}_{\mathrm{s}}^{\frac{2}{2}}}+\frac{\mathrm{t}}{\mathrm{q}_{\mathrm{v}}}$ \\
\hline & & The intra-particle diffusion model & $q_{t}=k_{i d} t^{\frac{1}{2}}+C$ \\
\hline
\end{tabular}




\section{Physico-chemical Characterization}

\section{RESULTS AND DISCUSSION}

1.1. XRD

Figure (1) shows the XRD pattern of (ZSnc) of unmodified and modified in the presence SDS at $10^{-3} \mathrm{~mol} / \mathrm{l}$, as a representative example. The unmodified sample characterized with an amorphous structure (Fig. 1 a). The mean diffractions peaks of hexagonal wurtzite $\mathrm{ZnO}$ at $2 \theta=$ $31.71^{\circ}, 34.48^{\circ}, 36.23^{\circ}, 47.53^{\circ}, 56.47^{\circ}$ and $62.78^{\circ}$ were observed in case of ZSnc sample (Fig.1b). These are related to (100), (002), (101), (102), (110) and (103) planes of the $\mathrm{ZnO}^{[11]}$. Therefore, ZSnc interacts with the SDS-bilayer installation and affectstheir packing and degree of ordering. This is due to varying degrees ofpreferred growth orientation along c-axis of the $\mathrm{ZnO}$ phase[12,13].The Scherrer formula is used to calculate crystalline size.

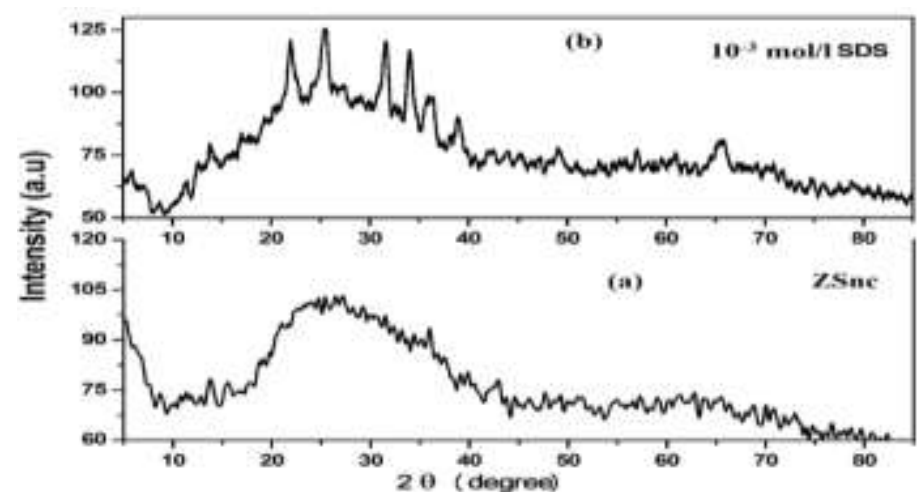

Fig.2: (a) XRD Patters of ZSnc unmodified,(b) modified with $10^{-3} \mathrm{~mol} / \mathrm{l}$ SDS.

\subsection{TEM}

Figure ( 2 a) elucidates the influence of surfactant on aggregation of nanoparticles using TEM images.50\% ZSnc unmodified evident high aggregation of particles as appeared in Fig 2(b). However, $\operatorname{SDS}\left(10^{-3} \mathrm{~mol} / \mathrm{l}\right.$ ) has a low aggregation hybrid morphologies (spherical, nano sheets) particles with mean diameter $6 \mathrm{~nm}$. The low aggregation behavior in case modified samples due to space steric effect, which produced by the organic groups located on the surface of adsorbant decrease the agglomeration of silica ${ }^{[14]}$.
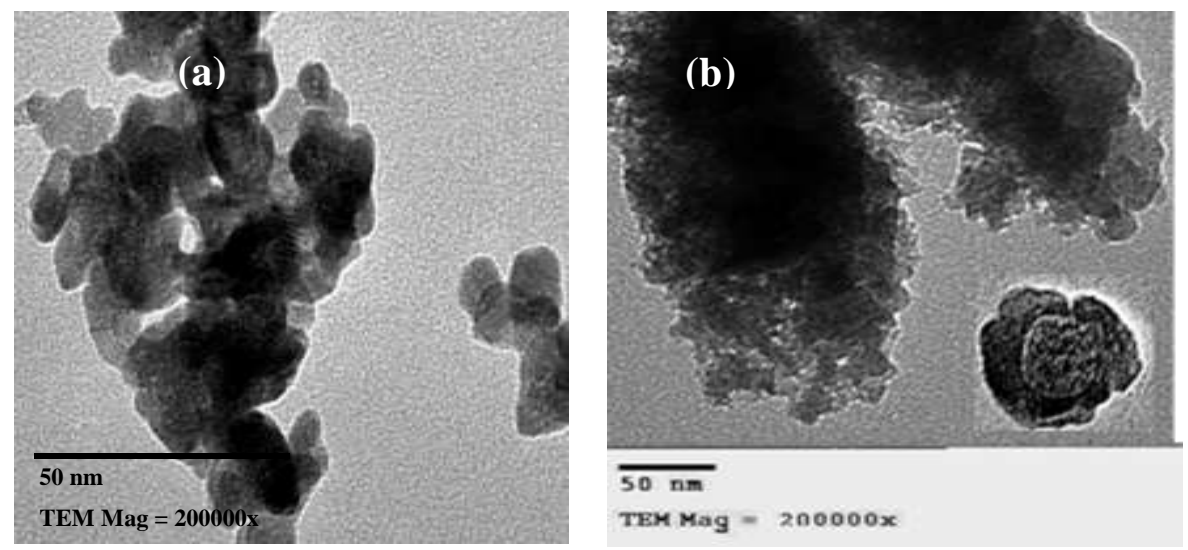

Fig.2:(a)TEM image of modified with $10^{-3} \mathrm{~mol} / \mathrm{l}$ SDS, and (b) pure nanoparticles. 
Abeer Emamet al.

\subsection{Surface area measurements}

The nitrogen adsorption/desorption isotherms was given in Figure (3a). All prepared samples exhibited type IV isotherm, which is the typical adsorption profile for mesostructure $^{[15]}$. The pore size distribution obtained from the desorption branch of the isothermsis elucidated inFigure (3b).The textural properties, including specific surface area $\left(\mathrm{S}_{\mathrm{BET}}\right)$, monolayer volume $\left(\mathrm{V}_{\mathrm{m}}\right)$, total pore volume $\left(\mathrm{V}_{\mathrm{P}}\right)$, mean pore diameter derived from the $\mathrm{N}_{2}$ adsorption/desorption isotherms and pore size distributions of all binary oxides are summarized in Table (2).

Table2. Surface area and pore size distribution analysis of (ZSnc) pure nanoparticle and modified with $10^{-3} \% \mathrm{~mol} / \mathrm{l} \mathrm{SDS}$.

\begin{tabular}{|c|c|c|c|c|c|}
\hline Samples & $\begin{array}{c}\mathbf{S}_{\mathbf{B E T}} \\
\left(\mathbf{m}^{\mathbf{2}} / \mathbf{g}\right)\end{array}$ & $\begin{array}{c}\mathbf{V}_{\mathbf{m}} \\
\left(\mathbf{c m}^{\mathbf{3}} / \mathbf{g}\right)\end{array}$ & $\begin{array}{c}\mathbf{V}_{\mathbf{P}} \\
\left(\mathbf{c m}^{\mathbf{3}} / \mathbf{g}\right)\end{array}$ & $\begin{array}{c}\mathbf{r}^{-} \\
(\mathbf{n m})\end{array}$ & $\begin{array}{c}\text { Mean porediameter } \\
(\mathbf{n m})\end{array}$ \\
\hline ZSnc & 188.15 & 0.05 & 0.24 & 2.5 & 2.1 \\
SDS & 119.6 & 0.03 & 0.22 & 3.6 & 3.2 \\
\hline
\end{tabular}

The addition SDS leads to decrease the $S_{B E T}$ value of $Z$ Snc(Table 2). $V_{m}$ and $V_{p}$ are conversant with the behavior of $\left(\mathrm{S}_{\mathrm{BET}}\right)$. The pore size distribution curves of unmodified and modified ZSnc show a relatively narrow distribution in mesopores range with an average pore diameter of $2.1 \mathrm{~nm}$ and $3.2 \mathrm{~nm}$, respectively. The highest pore diameter is found in SDS modified nanoparticles and this result is compatible with $\left(\mathrm{S}_{\mathrm{BET}}\right)$ so. The surface modifications provided newly available sites for MB adsorption. The surface modifications caused ruptures on nanoparticles, and opened new possible paths for the influent flow, thus reaching new places for adsorption. The nano-particles porosity was changed, therefore, the influent flow pattern and the mass transfer rate were modified.

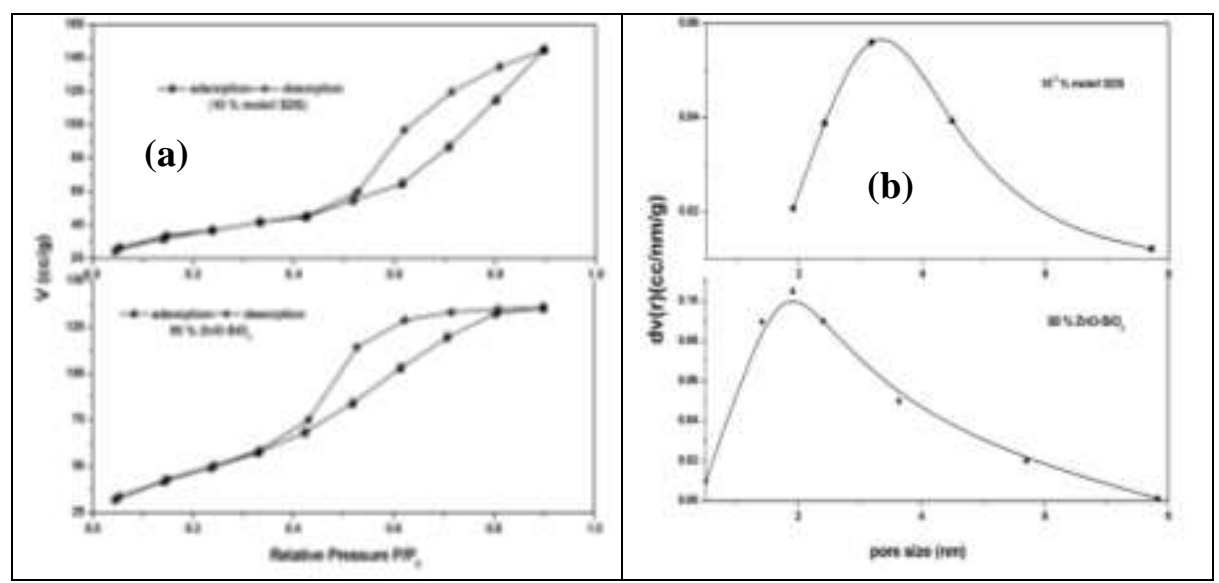

Fig.3: (a) Nitrogen adsorption-desorption isotherms of pure nanoparticles and modified with $10^{-3} \mathrm{~mol} / \mathrm{l} \mathrm{SDS}(\mathrm{b})$ Pore size distribution as the latter.

\subsection{Adsorption evaluation}

\subsubsection{Effect of adsorbent concentrations}

Figure (4) shows the effect of contact time on dye removal in the presence of ZSnc prepared at different concentrations from SDS. The dye removal percentage was increase by increasing the reaction time. The optimum dye removal percentage was observed in case ZSnc prepared in the present of $10^{-3} \mathrm{~mol} / \mathrm{l} \mathrm{SDS}$. the equilibrium dye removal value was 
reached after 20 min from starting reaction. After that, the removal of dye was increased slowly due to particle aggregation resulting from high adsorbent mass ${ }^{[16]}$. The high are removal in case in modified samples was attributed to morphological, surface and low aggregations parameter.

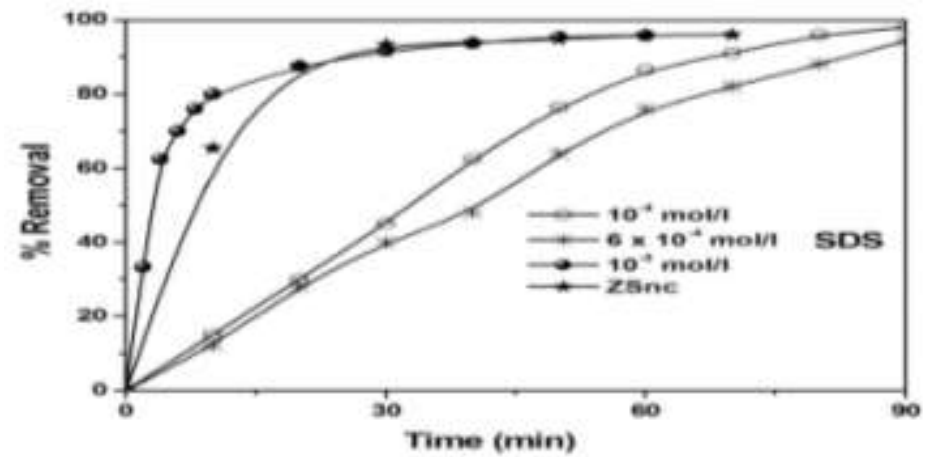

Fig.4.MB removal \% as a function of time at pure ZSnc and different concentrations of SDS.

\subsection{Langmuir isotherm.}

The Langmuir adsorption isotherm was progressed to elucidate the adsorption of gas on the solid surface. The Langmuir equation was listed in Table (1). It evidences that the presence of monolayer as well the surface is strongly homogeneous ${ }^{[17]}$, whereas, $\mathrm{Q}_{\max }$ is a constant indicates to adsorption capacity $(\mathrm{mg} / \mathrm{g})$ and $\mathrm{b}$ is Langmuir constant associated to energy of adsorption (Table 3). The fundamental chartered of Langmuir isotherm can be evident by dimensionless separation factor, separation factor, the value $R_{L}$ indicates whether the isotherm is unfavorable $\left(R_{L}>1\right)$, linear $\left(R_{L}=1\right)$, favorable $\left(0<R_{L}<1\right)$ or irreversible $\left(R_{L}=0\right)^{[18]}$. Langmuir was adsorption isotherms for MB adsorption in Figure (5a).

\subsection{Freundlich isotherm.}

It is an ultimate trendy model for a single solute system,depends on the apportionment of solute between an aqueous phase and solid phase at the stable ${ }^{[19]}$. Freundlich model depicts the adsorption within limited range only.Freundlich equation was listed in Table1;'n' values are among 1 and10 that represent suitable adsorption ${ }^{[16]}$. Freundlich isotherms adsorption for (MB) viewed as in Figure (5b).
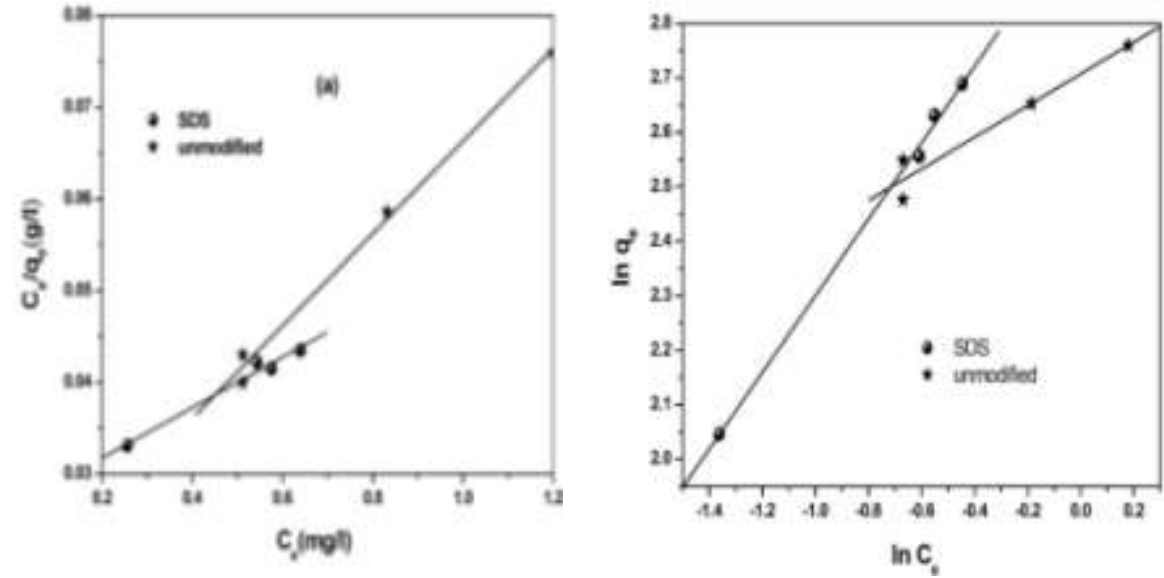

Fig.5: (a) Langmuir, (b) Freundlich, adsorption isotherms for MB adsorptionover unmodified and modified by SDS.

Table 3. Isotherms models for the adsorption of $\mathrm{MB}\left(5 \times 10^{-5} \mathrm{~mol} / \mathrm{l}\right)$ at $10^{-3} \mathrm{~mol} / \mathrm{l}$ SDS modified ZSnc (adsorbent mass: $10 \mathrm{mg}$ and $\mathrm{pH} 7$ ) 
Abeer Emamet al.

\begin{tabular}{|c|c|c|c|}
\hline Isotherm models & parameters & $\underline{\text { ZSnc }}$ & $\underline{\text { SDS }}$ \\
\hline$\underline{\text { Langmuir }}$ & $\begin{array}{l}Q_{\max }(\mathbf{m g} / \mathbf{g}) \\
R_{L}(\mathbf{L} / \mathbf{m g}) \\
b(L / g) \\
R^{2}\end{array}$ & $\begin{array}{c}19.85 \\
0.02 \\
3.2 \\
0.99\end{array}$ & $\begin{array}{c}37 \\
0.6 \\
1 \\
0.98\end{array}$ \\
\hline$\underline{\text { Freundlich }}$ & $\begin{array}{l}\mathbf{K}_{\mathbf{f}}(\mathbf{m} / \mathbf{g}) \\
\mathbf{1} / \mathbf{n} \\
\mathbf{R}^{2}\end{array}$ & $\begin{array}{c}15 \\
0.29 \\
0.94\end{array}$ & $\begin{array}{c}20 \\
0.7 \\
0.99\end{array}$ \\
\hline
\end{tabular}

\subsection{Analysis of isotherm results.}

The analytical adsorption parameters and correlationcoefficients $\mathrm{R}^{2}$ calculated from isotherm equations Langmuir and Freundlich using different adsorbate were collected (Table 3). It can be seen that models provided a good fit(Fig. 5). The correlationcoefficients calculated for the Langmuir equation fitting are similar to than the ones obtained in the case Freundlich equation. However that Langmuir describes better the experimental system. This is due to the experimental data reaches a saturation plateau at high $\mathrm{C}_{\mathrm{e}}$. This saturation tendency is not included in Freundlich model. Hence, it indicates that the surface area of the adsorbent is carried by the monolayer of the adsorbate. The $\mathrm{R}_{\mathrm{L}}$ value obtained from Langmuir isotherm was 0.6 for modified.This is indicating a favorable adsorption. A value of $1 / \mathrm{n}$ below one indicates poor adsorption for Freundlich isotherm. Over and above,the value of slope equal to $1 / \mathrm{n}$ don't equal to the value of intercept $\log \mathrm{k}$.

\subsection{AdsorptionKinetics}

The kinetics of adsorption of methylene blue on 50\% ZSnc prepared in the presence different SDS concentration has been evaluated. The experimental data were examined by pseudo-firstorder kinetics, pseudo-secondorder kinetics and intra-particle diffusion to understand the dynamics of adsorption process Table (4).All kinetics of adsorption equations were listed in Table (1).

\subsubsection{Pseudo-first ordermodel}

The pseudo-firstorder kinetic model Known as the Lagergren kinetic equation is widely utilized to understand the kinetic behavior of the system ${ }^{[20]}$. Whereas $\mathrm{q}_{\mathrm{e}}$ and $\mathrm{q}_{\mathrm{t}}$ are the amounts of dye adsorbed at equilibrium at time $\mathrm{t}\left(\mathrm{mgg}^{-1}\right), \mathrm{k}_{1}$ is the pseudo first order rate constant $\left(\mathrm{min}^{-1}\right)$, as in Fig. 6a and Table (4).

\subsubsection{Pseudo-second ordermodel}

The pseudo-secondorder model is based on the presumption that the rate limiting step perhaps chemisorption that involves valence forces through sharing or electron exchange with in the adsorbent and the adsorbate ${ }^{[21]}$. Whereas $\mathrm{q}_{\mathrm{t}}$ and $\mathrm{q}_{\mathrm{e}}$ are the amount of dye adsorbed at equilibrium at time t. The equipoise rate constant of pseudo-second order model $\left(\mathrm{k}_{2}\right) \mathrm{g} / \mathrm{mol}$.min, as in Figure (6b) and Table (4).

\subsubsection{Intra-particle DiffusionModel}

The evaluation of the diffusion mechanism is not conceivable from pseudo first order and second order kinetic mode ${ }^{[22]}$. The intra-particle diffusion model means that the plot of $\mathrm{q}_{\mathrm{t}}$ versus $\mathrm{t}^{1 / 2}$ should be linear, as in Fig 6d.Otherwise, the intra-particle diffusion is the controlling step if the lines pass by the origin otherwise some degree of boundary layer control exists then theextent of the thickness of boundary layer can be known from the values 
61

Effect of anionic surfactant on mesoporous particles for removal of methylene blue

of intercept. The larger the value of intercept is, the greater the effect of boundary layer can $\mathrm{be}^{[23]}$.

Table 4: Kinetic models for the adsorption of $\mathrm{MB}\left(5 \times 10^{-5} \mathrm{~mol} / \mathrm{l}\right)$ at $10^{3} \mathrm{~mol} / \mathrm{l}$ SDS modified ZSnc(adsorbent mass: $10 \mathrm{mg}$ and $\mathrm{pH}$ 7).

\begin{tabular}{|c|l|c|c|}
\hline \multicolumn{1}{|c|}{ Kinetic } & \multicolumn{1}{|c|}{ parameters } & ZSnc & \multicolumn{1}{|c|}{$\begin{array}{c}\text { SDS } \\
\text { at } \begin{array}{c}\text { qe.exp=14.7 } \\
\text { (mg/g) }\end{array}\end{array}$} \\
\hline Pseudo-first-order model & $\mathbf{q}_{\text {e.cal }}(\mathbf{m g} / \mathbf{g})$ & 8.7 & 7.7 \\
& $\mathbf{K}_{\mathbf{1}}\left(\mathbf{m i n}^{-1}\right)$ & 0.09 & 0.09 \\
& $\mathbf{R}^{\mathbf{2}}$ & 0.96 & 0.93 \\
\hline \multirow{2}{*}{ Pseudo-second-ordermodel } & $\mathbf{q}_{\text {e.cal }}(\mathbf{m g} / \mathbf{g})$ & 12.9 & 15.4 \\
& $\mathbf{K}_{\mathbf{2}}\left(\mathbf{g ~ m g}^{-1} \mathbf{m i n}^{-\mathbf{1}}\right)$ & 0.02 & 0.03 \\
& $\mathbf{R}^{\mathbf{2}}$ & 0.99 & 0.99 \\
\hline \multirow{2}{*}{ Intra-Particle-diffusion } & $\mathbf{C}$ & 0.07 & 0.25 \\
& $\mathbf{K}_{\text {diff }}\left(\mathbf{m g ~ g}^{-\mathbf{1}} \mathbf{m i n}^{-\mathbf{1}}\right)$ & 2.44 & 4.6 \\
& $\mathbf{R}^{\mathbf{2}}$ & 0.99 & 0.98 \\
\hline \multirow{2}{*}{ Intra-Particle-diffusion } & $\mathbf{C}$ & 10.8 & 11.9 \\
& $\mathbf{K}_{\text {diff }}\left(\mathbf{m g ~ g}^{-\mathbf{1}} \mathbf{m i n}^{-\mathbf{1}}\right)$ & 0.15 & 0.37 \\
& $\mathbf{R}^{\mathbf{2}}$ & 0.96 & 0.96 \\
\hline
\end{tabular}

Where $k p$ is the intra-particle rate constant $\left(\mathrm{gmol}^{-1} \cdot \mathrm{min}^{1 / 2}\right)$ and $\mathrm{C}$ is the intercept.
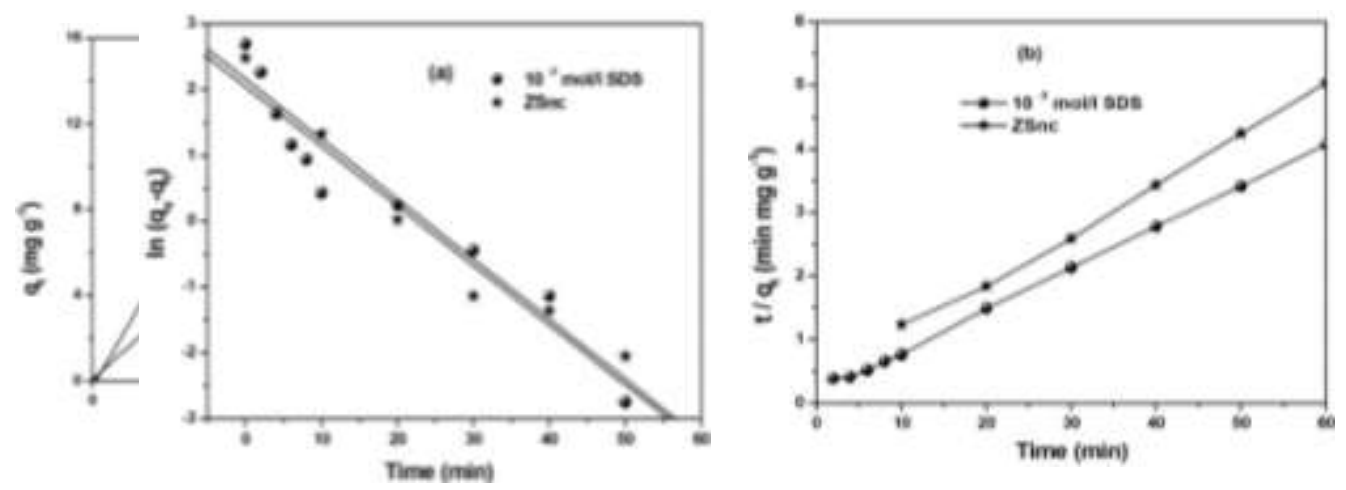

Fig.6. (a) Pseudo-first order, (b) Pseudo-second order, (d) Intra-particle diffusion model plot of dye adsorbed (MB) over unmodified and modified by SDS.

\subsubsection{Analysis of Kinetic results}

The first order models, the experimental $\mathrm{q}_{\mathrm{e}}$ values did not agree with the calculated ones, obtained from the linear plots (Table 4). This is indicating that the first order model does not reproduce the adsorption kinetics of $\mathrm{MB}$ on the modified adsorbate. Thecorrelation coefficients for the pseudo second order are close to 1.0 for MB. The pseudo-secondorder model is more likely to predict the behavior over the whole experimental range of adsorption. The calculated $\mathrm{q}_{\mathrm{e}}$ values fit quite well with the experimental data.The pseudo first order kinetic curves do not fit with the experimental data in case of intra-particle diffusionmodel.Other processes may also control the adsorption process, as the lines do not pass through the origin and all the processes may occur simultaneously. 
Abeer Emamet al.

\section{Conclusions}

$\mathrm{ZnO}-\mathrm{SiO}_{2}(\mathrm{ZSnc})$ was prepared by sol-gel method in the present of different SDS concentrations. The physicochemical properties have studied using XRD, TEM, and $\mathrm{S}_{\mathrm{BET}}$. The adsorption efficiency of the nanoparticle was evaluated by adsorption of dye. The analyses of data by kinetic and isotherm model, the pseudo second order reaction is the best model and follow the Langmuir and Freundlich isotherm. Also, the Langmuir is a good model. The modified ZSnc in the present SDS considered a promising advanced adsorbent in environmental pollution cleanup.

\section{REFERENCES}

1- W.J. Cosgrove and F.R. Rijsberman (2014).World water vision: making water everybody's business, Routledge.

2- K.T. Chung (2000). Mutagenicity and carcinogenicity of aromatic amines metabolically produced from azo dyes, Revs. C18 (1):51-74.

3-V.M. Gun'ko; V.M. Bogatyrov; O.I. Oranska and L.I. Borysenko (2013).Structural features of $\mathrm{Zn}_{x} \mathrm{O}_{y} /$ nanosilica composites,Appl. Surf. Sci., 276: 802-809.

4- P. Dhage; A. Samokhvalov; D. Repala; E.C. Duin; M. Bowman and B.J. Tatarchuk (2010).Copper-Promoted $\mathrm{ZnO} / \mathrm{SiO}_{2}$ Regenerable Sorbents for the Room Temperature Removal of $\mathrm{H}_{2} \mathrm{~S}$ from Reformate Gas Streams, Ind. Eng. Chem. Res. 49 (18): 83888396.

5- G.W. Kalb and R.B. Curry (1969).Determination of surface area by surfactant adsorption in aqueous suspension. I. Dodecylamine hydrochloride, Clay. Miner.17:47-57.

6-R.A. Mackay (1987). Solubilization, in: Martin J. Schick (Ed.), Nonionic Surfactants: Physical Chemistry, Surfactant Science Series,M. Dekker Inc., New York, pp. 308-314.

7-D.Mayers (1988). Surfactants in solution: micelle and related association phenomena, in: Surfactant Science and Technology, VCH Publishers Inc., pp. 104-106.

8-S. Göktürk and M.Tunçay (2003).Spectral studies of safranin-O in different surfactant solutions, Spectrochim.Acta. A. Mol. Biomol. Spectrosc.59 :1857-1866.

9-R.V. Pereira and M.H. Gehlen (2005).Fluorescence of acridinic dyes in anionic surfactant solution, Spectrochim . Acta. A. Mol. Biomol. Spectrosc.,61 : 2926-2932.

10- K.K. Karukstis; D.A. Savin; C.T. Loftus and N.D. D’Angelo (1998).Spectroscopic studies of the interaction of methyl orange with cationic alkyl trimethyl ammonium bromide surfactants. J. Colloid. Interface. Sci. 203:157-163.

11- M.G. Jeong; E.J. Park;B. Jeong; D.H. Kim and Y.D. Kim (2014).Toluene combustion over $\mathrm{NiO}$ nanoparticles on mesoporous $\mathrm{SiO}_{2}$ prepared by atomic layer deposition. Chem. Eng. J., 237: 62-69.

12-Y.Ni; G. Wu; X. Zhang; X. Cao; G. Hu; A. Tao; Z.Yang and X. Wei (2008). Hydrothermal preparation, characterization and property research of flowerlike $\mathrm{ZnO}$ nanocrystals built up by nanoflakes, Res. Bull. 43:2919-2928.

13-E.M.P. Steinmiller and K.-S.Choi (2007).Anodic construction of lamellar structured ZnO films using basic media via interfacial surfactant templating, Langmuir, 23:12710-12715.

14-Z. Luo; R.Y. Hong; H.D. Xie and W.G. Feng (2012).Anodic construction of lamellar structured $\mathrm{ZnO}$ films using basic media via interfacial surfactant templating, Powder Technology 218: 23-30.

15- F. Rouquerol; J. Rouquerol and K. Sing, (1999). Adsorption by Powders and Porous Solids: Principles, Methodology and Application, London, Academic Press.

16-M.R. Malekbala; S.Hosseini; S. Kazemi-Yazdi; S.M. Soltani and M.R. Malekbala (2013).On the utilization of a lingo cellulosic waste as an excellent dye remover: Modification, characterization and mechanism analysis. Chem. Eng. J., 229 : 257-266. 
Effect of anionic surfactant on mesoporous particles for removal of methylene blue

17- A.B. Pérez-Marín; V.M. Zapata; J.F. Ortuño; M. Aguilar; J. Sáez and M. Lloréns(2007).Removal of cadmium from aqueous solutions by adsorption onto orange waste, J. Hazard. Mater. 139(1): 122-131.

18- S. Arivoli; V. Nandhakumar; S. Saravanan and S. Nadarajan (2009).Adsorption Dynamics of Copper ion by Low Cost Activated Carbon, Arab. J. Sci. Eng., 34 (1A): 112.

19- V.C. Taty-Costodes; H. Fauduet; C. Porte and A. Delaccroix (2003). Removal of Cd(II) and $\mathrm{Pb}(\mathrm{II})$ ions from aqueous solutions by adsorption onto sawdust of pinussylvestris, $\mathrm{J}$. Hazard. Mater. B105:121-142.

20- S. Mohan; N.Rao and J. Kartikeyan (2002).Adsorptive removal of direct azo dye from aqueous phase onto coal based sorbents- a kinetic and mechanistic study, J. Haz. Mat. B90:189-204.

21- Y. Ho and G. McKay (1998) .Sorption of dye from aqueous solution by peat, Chem. Eng. J. 70 (2) :115-124.

22- W.J. Weber; J.C. Morriss and J. Saint (1963).Kinetics of adsorption on carbon from solution, Eng. Div. Am. Soc. Civ. Eng,.89: 31-60.

23- A.S. Özcan; B. Erdem and A.Özcan (2005). Adsorption of Acid Blue 193 from Aqueous Solutions onto BTMA-Bentonite, Colloids Surf. A: Physicochem. Eng. Asp.266 :73-81.

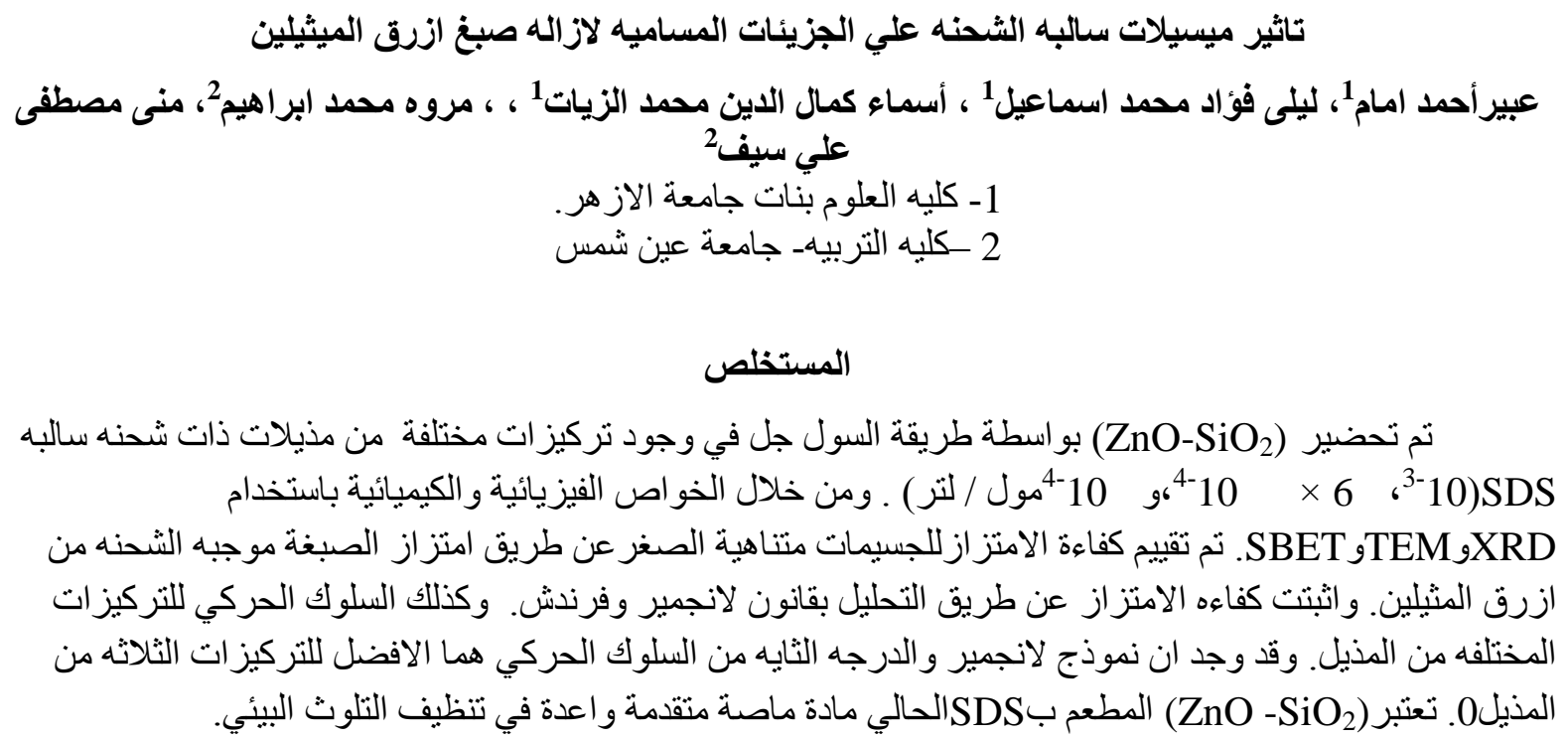

